price on the fashion market. There are now $330 \mathrm{mink}$ farms in England which export about $£ 1$ million worth of pelts a year. An average pelt sells for $£ 10$, and about 70 pelts may be needed to make a coat. The young are born in March at an average of five to a litter; raised on a diet of lights and offal, they are ready for pelting in November. For those with a feel for mink, the farming can be a profitable business.

\section{Help for the Tropics}

AN appeal for $£ 2$ million has been launched by the United Kingdom Foundation for the International College of Tropical Medicine. This foundation, an entirely independent and academic organizationthe conception of Mr Geoffrey Myres, a New Zealand surgeon with wide experience in the tropics-has been set up to serve the cause of medicine in tropical and subtropical countries.

The international college aims to help countries in which the shortage of doctors, nurses and other medical staff is acute, by establishing postgraduate tropical medical centres. At the moment, postgraduate tropical medicine training is only available outside the tropics as, for example, at the schools of tropical medicine in Britain. The centres envisaged by the foundation will comprise a hospital for training in clinical tropical medicine at postgraduate level, a school of tropical, social and preventive medicine and a research institute. Under the constitution of the college, it will be able to organize study and correspondence courses, conduct examinations and disseminate information through journals, textbooks, visual aids and libraries.

A positive step has already been made by the donation of land by the government of Uganda for the establishment of the first centre. Two other tropical countries have also offered land. It is hoped to establish other centres in Asia and Latin America. Specialists in tropical medicine from 15 countries form the advisory council, under the presidency of Professor T. A. Lambo, dean of the Medical Faculty, University of Ibadan. The council is backed by a separate board of trustees to manage financial affairs, and by an executive office with a provost to administer the college on behalf of the board and council. Charitable foundations are being established in several countries. The United Kingdom appeal, the first to be made, aims to raise enough money to enable the college to realize its objectives, and in particular to meet the capital expenses of the establishment and running costs of the first centre. Prominent people from the medical, scientific and other professions and industrial and business life are included in the membership of the UK council and exceutive committee.

\section{Bringing Gas Ashore}

NoвоDy yet knows what natural gas in Britain will cost. Despite this, the Gas Council aims to supply natural gas to all area boards by 1970, and the total expenditure on transmission and distribution over the next five years will be about $\mathfrak{f} 800$ million. The first of the now pipelines, from Easington in Yorkshire, where gas comes ashore from the West Sole field of the British Petroleum Company, is already transmitting gas. Since July 1967, it has been feeding an average of 100 million cubic feet of natural gas a day into the national transmission system. Details have now been released of a new gas terminal now under construction at Bacton on the Norfolk coast. Initial supplies will go into the Gas Council's No. 2 feeder main, now almost complete.

The council aims for a huge capacity for this terminal, the first part of which is expected to be in operation by the middle of 1968 . It is intended to have a maximum capacity of 4,000 million cubic feet of natural gas a day, nearly four times as much gas as is currently used throughout the whole country. The terminal will eventually handle natural gas from the 3 major fields discovered off the Norfolk coast-the Leman and Indefatigable fields which the Shell-Esso Group and Gas Council-Amoco Group share, and the Hewett Bank field, shared by the Arpet and Phillips Groups. Facilities being constructed for the Gas Council are for the reception of the gas and its distribution. Among the principal processes will be filtering of the gas, check-metering if required, heating, blending, odorizing and methanol injection.

A group of architects has been appointed for the design of the terminal, and most of the contracts awarded. The clients are taking due notice of the need for proper landscaping; the basic design for the Gas Council and Shell-Esso, which includes tree planting and grassed earth, has been agreed with the Royal Fine Art Commission. Clearly the hope is that in the rush to get natural gas to the public within the framework of the present economic restrictions, the amenities of the Norfolk coastline will not be sacrificed in aid of progress.

\section{Hydraulics}

The Ministry of Technology's Hydraulics Research Station, at Wallingford, Berkshire, has two main functions-to investigate specific problems in the field of civil engineering hydraulics for organizations both in the United Kingdom and overseas, and to conduct research in support of this work. The station's activities in 1966 are recorded in its annual report, just published (HMSO, 11s.). Services of the station are provided on a non-profit repayment basis and they appear to be much in demand; 140 investigations were in progress during the year.

One interesting project involves the possible use of synthetic seaweed as an aid in building up beaches. The station is trying to find out whether this material will promote onshore transport of sand and, if so, by what mechanism. Using a special polypropylene of normal density but modified elasticity, a model seaweed bed was laid offshore from a beach in a wave flume. The scale of the model was $1: 10$, and coal particles were used as the bed material. In such a flume, beach changes could only result from changes in onshore-offshore transport. Accumulation on the beach necessarily implied that sediment had come in from offshore, in contrast to the situation on a real beach where accumulation can be caused by changes in littoral drift. With the seaweed in position, the sea-bed eroded offshore and build-up of the beach occurred. Measurements were carried out to find a possible explanation for this. Full-scale tests were made at an offshore synthetic seaweed installation at Bourne- 